\title{
VESTIGES OF EARLY MAYA TIME CONCEPTS IN A CONTEMPORARY MAYA (GUBULCO ACHI) COMMUNITY: IMPLICATIONS FOR EPIGRAPHY*
}

\author{
Helen Neuenswander \\ Summer Institute of Linguistics
}

Bishop Diego de Landa (Tozzer, 1941: 27, 63-4) showed that the knowledge of highly sophisticated methods for conceptualizing and recording the passage of time was the peculiar possession of specialists in the Maya society. Nash (1957: 149) correctly predicted the demise of such specialists in the geographic area occupied by Cubulco, Baja Verapaz, "south of a line which runs through Nebaj, San Cristobal, and Santa Cruz in Guatemala" and suggested that their demise

* Presented at 77th. Annual Meeting, American Anthropological Association, Los Angeles, California, November 14-18, 1978.

1 The municipio of Cubulco is located in the departamento of Baja Verapaz in the central highlands of Guatemala. Cubulco Achí, a Quichean language, is spoken only in this municipio; approximately 75 percent of the $20000 \mathrm{Cu}$ buleros speak Achí; the remainder speak Spanish. The Achí do not refer to themselves by this name (achí means "man"), but as Aj-Cubul winak "ofCubulco people." Fray Dionisio de Zúñiga, between the years of 1610 and 1636 , wrote his works in "the C'achi language of Santiago Cubulco" (Estrada Monroy, 1972). The municipio covers an area of approximately 60 square kilometers and has jurisdiction over seventeen aldeas (hamlets which may boast a school, marketplace, store, and church) and twenty-two caserios (scattered groups of houses with no formal organization). The town center is located in a valley at an altitude of 880 meters, but some of its aldeas in the surrounding mountainsides are located at altitudes of up to 2000 meters. The linguistic environs include Rabinal Achí (Quichean) on the east, Pocomchí on the northeast, Uspantec on the northwest, the Quiché dialects of Sacualpa and San Andrés Sacabajá on the west, and the Quiché of Joyabaj on the southwest. On the south, the Spanish-speaking towns of Granados and El Chol separate Cubulco from the Cakchiquel towns of San Juan and San Pedro Sacatepequez. Mayers (1966: 274) calculates the time depth between Achí and Quiché to be aproximately 13 centuries, in contrast to approximately 5 centuries between Achí and Cakchiquel.

Data for this paper have been collected by the author from 1953-1978, while working with the Summer Institute of Linguistics. 
may be traced to the failure to regularly elect them, incorporating them into the existent political structure. The longtime absence of such elected calendar specialists in Cubulco leads one to expect that these descendants of the ancient Maya have been divested of the means for precisely calculating time. Suprisingly, such is not the case. The Cubulco Achi nonspecialist possesses a well developed system for pinpointing an event in time several years backward or forward without recourse to the numeration, day names and month names of either the Gregorian calendar or the 260-day or 365-day cycles utilized by their ancestors. While the twenty day names of the 260-day divinatory calendar are known to a few native priests ( $a h$ ' $i h^{2}$ "of days/ sun"), their use is mainly restricted to divinations.

The foregoing would seem to suggest that the demotion of the Achi calendar specialists precipitated the development of a new time system or the adoption of a foreign system. Quite to the contrary, the hypothesis I wish to propose here is that the Maya layman has retained, from earliest times, a high level of proficiency in the art of telling time and that the unit upon which his most exacting calculations are based is now, as then, the lunar cycle. In order to test this hypothesis, it is necessary to consider the following: 1) the cognitive structure of time held by the Achi, 2) certain hieroglyphic structures displayed in the inscriptions and codices of the Classic Period (A. D. 250-900), and 3) apparent similarities in the current and ancient structures which imply survivals in the current structures. The presumptuousness of such a task has not evaded me, and I take into account both Thompson's encouragement and Vogt's warnings as I begin. Thompson said: "It is my conviction that we shall interpret the glyphs only by relying heavily on the beliefs, the religious symbolism, the mythology, and to a lesser extent, the everyday activites of the Maya, because such concepts surely are imbedded in the structure of each glyph" (1960: 34, 35). However, Vogt cautioned that "no ethnographer believes in the existence of survivals of beliefs and patterns of behaviour found 1300 years ago", but added that "we may be permitted to project current data back in time and to advance hypotheses about survivals that may profitably be further

2 Linguistic examples in Achí utilize the following phonemic representations: $\mathrm{a}, \mathrm{e}, \mathrm{i}, \mathrm{o}$, and $\mathrm{u}$ (with no short-long vowel contrast phonemic for Achí);

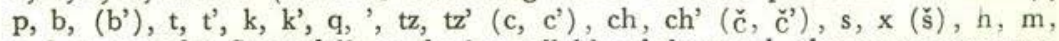
$\mathrm{n}, \mathrm{l}, \mathrm{w}, \mathrm{r}$, and $\mathrm{y}$. Stress falls on the last syllable of the word, phrase, or utterance. Symbols within parentheses give the usual I. P. A. (International Phonetic Alphabet) representations for the preceding phonemes. 
explored using archaeological, linguistic, and ethnohistoric data" (Vogt, 1969: 588).

Cognitive studies of contemporary Maya systems provide insights which could facilitate glyph decipherment in various ways: 1) Since cognitive studies make a point of identifying concepts linguistically, labels assigned to concepts may assist epigraphers searching for new forms and provide supportive evidence for phoneticizations of certain glyphs which have been previously proposed. The trend toward phonetic interpretation of the Maya Script, led by Knorozov (1958), has now progressed to the point where many, like Kelley, "view with considerable skepticism any claim that Mayan glyphs, other than numbers, can be divorced from the linguistic background of those who produced them" (Kelley, 1976: 166). 2) Through careful cognitive analysis, certain conceptual elements found to be emic to a given system will be deeply enough embedded in the time structure to demonstrate a relationship to genetic elements of the proto-system (Vogt, 1964: 22). The epigrapher is thus made aware of the semantic significance of glyphic representations. 3) In view of the fact that certain Achi concepts may be expressed either linguistically or by hand positions, and since some of the most commonly-used hand positions bear a definite resemblance to hand positions appearing in the glyphs, insights into glyph decipherment may also be gained in this area.

An example of insights into glyph structure, which may be provided by contemporary cognitive structures of the type of number 2) above, is the custom practiced among the Aguacatecs of northwest Guatemala of "planting" in the earth the end of a long slender stone ( $q a-k$ ' $u b$-il "our stone") whenever a child is born (personal communication with Harry McArthur). On each 260-day (tzolkin) anniversary of the young child's life, the parents return to the hillside where the stone was planted to burn incense and ask of the earth its continued protection of the child. It is entirely possible that this simple practice was the forerunner of the custom of erecting the ornate stelae which remain today, commemorating birth dates, anniversaries, and outstanding achievements of rulers. It has now been established by Proskouriakoff (1960: 454) that initial dates recorded on such stelae represent "something in the nature of a birth or name day of a ruler who accedes to power on the inaugural date" of that stela. Landa also mentioned stones called acantun "set-up stones" (Tozzer, 1941: 13-8) to which were applied the blood drawn from the earlobes of participants in the Uayeb "year's-end ceremonies." These were apparently similar to the Aguacatec stones in their function of representing people before the gods and receiving ritual meals on anniversaries. Another 
practice for which stones were utilized was that of counting (principally for calendrical calculations and divinations). Achi ahlah "to count" is possible derived from $a h$ "of, from" and lah "flat stones". Arvid Westfall (personal communication) reported a Kanjobal worship center in Coya (San Miguel Acatan, Huehuetenango) composed of a circle of stones, each stone representing a day god. Though unmarked, the owner recited the day names in order as he went around the circle.

The foregoing digression from the central topic of this study is for the purpose of illustrating that the concept represented by a glyph may be more important than the phonetic representation of that glyph. The "stone" glyph, which marks katun (20-year period) anniversaries in the Maya script may be called a tun, a $k^{\prime} u b$ or an $a b a h$, but chances are it was quickly recognized by the Maya, regardless of their dialect, as marking an anniversary or counting days, according to its context. The linguistic diversity of the vast area occupied by the Maya during the Classic Period made a standard phonetic reading difficult, especially in view of the frequent changes in the prestige language as power was wrested from one language group and assumed by another. For example, certain day glyphs show Kanjobal to be the logical base language for the construction of those particular glyphs, rather than Yucatec (Thompson, 1950: 106).

\section{Methodology}

The data for this study were collected over a period of 25 years in the rather ideal setting of a medical clinic for the Achi in Cubulco. Since concepts relating to time seemed to be the most evasive of analysis to my western mind, I developed the practice of jotting down in Achi anything which might help me locate events in time such as the expected date of delivery, the last day of menstruation, or the approximate time of onset of an illness. At first, direct questioning was singularly nonproductive. The stock answer to any question aimed at determining a given time with precision was: kin riq ti 'ahlanik "I can't count (time)." Gradually, however, the conversations began to generate more relevant information, as illustrated by the following dialogue:

"I have come to find out when you think I will deliver my child ( $k$ in riq $i$ 'ih 'I encoutner my day')."

"When did you last menstruate (kawil awik'il 'you-see yourmonth') ?" 
"A little bit is lacking for five months."

"Do you know the exact date you saw your month?"

"No, Mother. I do not know how to count days ('ahlah 'ih)."

"Then how do you know that it lacks but a little for five months?"

"Because I saw my month during Saint John (chupam i San Juan 'inside St. John')... you know, before Saint James (chuxe' $i$ Santiago 'at-its-root the St. James')... after the Day of the Cross (puwi $i$ Crus 'on-top-of the Cross')." (A frantic search through a calendar with Catholic saints' names produced the desired information: Saint John the Baptist's day was in June, Saint James', in July, and the Day of the Cross, in May.)

"So you last menstruated in June. But when during June?"

Mother-in-law interrupts:

"What was our grandmother doing when you last saw your month?" "Oh, she was but a child."

"Our grandmother?"

"Yes, the moon. She was over there (motioning with palm up and fingers pointed in the direction of the western horizon). She was just coming out, just showing herself. Now, our grandmother is old (hand sweeps across the sky from west to east, with the palm-up position rotating to a palm-down position and with the back of the hand exposed and the fingertips pointing toward the western horizon). After this moon is finished, after our grandmother is buried, and when she is new again-just three days old - then I will complete five months."

"Then, three days after the new moon in June, you saw your month?"

"I don't know what the month's name is."

"I'm sorry, the month's name is San Juan. Was the third day of the moon during San Juan the first day of your month?"'

"No. We always count from the fifth day."

"How did you learn all about what our grandmother is doing?"

"From my father. He said it is very important for me to always pay attention to what our grandmother is doing. But I'm not very good at it yet. After all, this is only my first child. Later on, I will know well the road our grandmother takes across the sky."

Having committed to memory the names of the saints and agricultural activities that substituted for the Gregorian month names, and having acquired a measure of expertise in interpreting information regarding the "age of our grandmother", I began to feel at home in the system. Sensing this, the patients also relaxed, and in an apparent attempt to recoup a portion of the verbage which they had so patiently frittered on me, they began, instead, to answer my questions regard- 
ing our grandmother's activities by motioning vaguely with one hand in the general direction of the moon's expected position in the sky. From these responses, I learned to frame the question which elicited them, namely, "Where was our grandmother when this happened?" I also learned that the Achi knows very well how to 'ahlah 'ih "count days". In my small world of a day being equivalent to a calendar date, it had not occurred to me that a day could be defined just as precisely in terms of what the moon looks like at night and where it appears at dark or at dawn.

\section{Counting Time ('ahlanik)}

The foregoing conversation provides a glimpse of the rich conceptual framework within which the Achi "counts his days" ('ahlah 'ih). It also illustrates that the area which is most highly developed and which provides the finest distinctions in locating an event in time is concerned with the moon. Lunar activity, however, is not limited to the age of the moon and its position in the heavens within a given month; in addition, the position of the moon determines the rainy and dry seasons which, in turn, form the year. Before becoming involved in the detail of such complex lunar phenomena, let us examine time elements which are apparently independent of lunar activity.

\section{Day ('ih) and Night (a'ob)}

The day and the sun, both translated 'ih, are equated in the Achi mind, even as they were in the minds of their ancestors who used a flower symbol to represent both concepts in the Maya script (Achi "flower" kotz'ih). The equivalence in the Achi mind becomes obvious when an attempt is made to translate the idea into another language. For example, an Achi said in Spanish, En el sol está bien; en la noche, no "In the sun it is all right but at night it is not," meaning that the was normal during the day but got sick at night.

The sun may also be referred to as "our father" (qa kahaw) even as the hieroglyphic representation of a flower may give way to the head variant form of an elderly male:

Are qa kahaw ka walihik'o k'ax pin ch'ek "When the sun rises, my knee pain begins" (When our father he gets-up there-is pain in-my knees). 
Are ke 'e qa kahaw... "When the sun goes down..." (When he goes our father...). Other ways of dividing the day are: sakirik "it dawns" or sakirbal "dawning"; pa'ih "during the day" (literally, "inday") identifies any part of the day up to sunset; sunset may be referred to as ka qah 'i'ih 'it goes-down the sun' or qahbal 'ih (nominalized form). The night $\left(a^{3} a b\right)$ is described as "entering" (kok $a$ 'ab "at dark"), as "centering" (tikil a'ab "midnight"), or as "whitening" (sakirik "it is dawning"). Cha'ab "at night" is equivalent in duration to pa'ih "during the day."

Forms which are universally employed in language to project time into the future or the past, and to space it, are well defined in Mayarelated languages and should be noted because of their potential for representations in the glyphs as affixes or as repetitions of the main element: earlier today (mier), yesterday (iwir), two days ago ( $k a$. bihir), three days ago (oxihir), tomorrow (chweq), day after tomorrow (kab'ih), daily ('ih 'ih), every two days (kakab 'ih), every three days (oxox 'ih). This same suffix (-ir) and mechanism of reduplication may be applied to larger time elements: every month ( $i k^{3}$ $i k^{\prime}$ ), every year (hunab hunab), a year ago (hunabir). Note that "a month ago" does not utilize the -ir suffix but postfixes a verb as in hun ik kanoq "one month left-behind" or prefixes it as in chupam $k a_{n} i$ i $k$ ' hun "during past (left-behind) the month one."

\section{Cycles of Days: The Week}

To facilitate calendrical calculations, the early Maya extended their vigesimal system of mathematics to create a "month" of twenty days and a "week" of five days, quite independent of the lunar count. With centuries of background in this system, it is little wonder that present-day Maya, in spite of the loss of this calendar, still measure time in periods of five days, twenty days, and their multiples. While there is no Achi term to denote the "month" of twenty days, nor the "week" of five days, the psychological reality of the 5-day and 20-day periods is validated by such practices as observing a fiesta over a period of twenty days, requiring sexual continence for twenty days before a fiesta, eating a special diet for twenty days postpartum, finishing the mountain harvest on the twentieth of the month (December), speaking of September 20 as being "forty days before All Saints Day" (rather than one month and ten days), having the abdomen bound for forty days postpartum, having the midwife give the first bath after the removal of the binder forty days postpartum, and finding it easier 
to remember events and to count in blocks of five days, as in the following:

$Y a \times k$ 'is diez dias u heqik i ya che, ya xu ch'ap quince "He has had diarrhea for ten days and he has begun fifteen days." (Already he-finished ten days its beginning the diarrhea to-him, already he-has grabbed fifteen.)

Chupam $i$ diez Awost xwilo $y$ xik'-aw $i$ quince "During the tenth (of) August she-saw-it and it-passed (on) the fifteenth."

Spanish numerals are often used for numbers of five and over. The symbolization however, is purely Maya. It is as though they were still counting with round objects (with a value of one) and long objects (with a value of five) and shells (with a value of zero). With a preference for the object valued at five, they finish one 5-day period and "grab onto" another.

Significantly, the 5-day period and the 7-day period may be conjugated differently than are other periods of days: ho'ob 'ih "five days" is referred to as hobix when thought of as a future period, or as hobixir when thought of as a past period. Wuqub 'ih "seven day." is referred to as wuqubix "a week from today" or wuqbixir "last week" ( $h$ often becomes $x$ in final position or when a terminal suffix is added e.g., tzukuk "to seek for", tzukuxik "to (his) seeking).

The wuqubix "7-day period" mentioned above fits so perfectly the concept of the 7-day week (referred to as ocho dias "eight days" in Spanish) that it is only by going back to the glyphs that the authenticity of the concept, as being Mayan, is maintained. Thompson cleverly identified a glyph which occurs with 7-day and 5-day periods, which he called the "bix" glyph and which he felt "corresponds to the numerical classifier bix ... and may indicate the intervals between markets" (Thompson, 1950: 179). Judging from the way the 7-day cycle is used in Cubulco to calculate phases of the moon, and recognizing that the cognitive validity of the 5-day cycle was based on its utilitarian function of dividing the 20-day month, I would like to recognize Thompson's acuity in isolating the glyph and in associating it with the 5- and 7-day periods but, on the basis of Achi data, reject his conjectures regarding the linguistic derivation of bix and the significance of the associated time periods. It seems obvious that, for the Achi at least, blix is derived from the final $-b$ of the numeral plus the ' $i$ m morpheme for day and the $-x$ affix mentioned above.

In providing examples to demonstrate the importance of these 7-day periods to the Achi, the main obscurant is the switch from Achi to Spanish when dealing with numbers of five and over. This tends to 
suggest that the concept as well as the form is borrowed,- a suspicion which I feel is definitely unwarranted. The importance of the 7-day period will be again stressed in the section dealing with the moon; the Spanish form for "week" semana is sometimes substituted for wuqubix "seven-days". When the period takes in two 7-day periods, quince dias " 15 days" is used; three weeks is spoken of as either veinte dias "20 days" or veintidos dias " 22 days":

Wuqubix kwartah panoq, pa quince dias ka k'iso "In 7 days begins the fiesta, in 15 days it will finish" ("seven-days-ahead it-isslept over-there" is an ancient frozen expression for first night of ritual).

Ocho dias xik'aw i alaxbal xwilo pa q'isbal re "Eight days havingpassed the birth-time (Christmas Eve) I saw-it for last-time of-it (last time)."

Chupam $i$ seman ka k'unik, kwil tan chik $i$ wik'il "In the week that comes, I-well-see again the my-month."

Wuqubxir, rth, $i$ qatit, $x k$ 'is $i$ oxib ik' "Last week when our grandmother was old, made three months" ("seven-days-ago, old the our-grandmother, it-finished the three months").

The Achi, while not having adopted the Gregorian month names into their system of "counting days", have taken full advantage of the names of the week days as convenient time-dividers within the lunar cycle:

Ka k'is $i$ oxib ik' chupam i martes ka k'unik "It will be three months on this coming Tuesday." ("It finishes the three months during the Tuesday it-is coming".)

Some young girls have grown indolent about watching their grandmother's activities and count time by the week only:

$X$ in koh ta retalil wach xo'on qatit, xa pa semana weta'am chi ya $x k$ 'is $i$ kahib, ch'apom chik $i$ ho'ob "I put not attention-to what she-did our-grandmother, only by weeks I-know that already it-finished the four (months) and has-grabbed already the five (months)."

$N a^{3} b e$ semana chupam ocho meses are xin tzaqik "It was the first week of my eighth month when I aborted" ("First week during eight months when I fell").

$Y a$ ka k'is kahib semana pa lunes wakubix ka k'unik "Four weeks will be up on a week from this coming Monday". ("Already it finishes four weeks on Monday seven-days it comes.") 


\section{Vehicles for Carrying Time Concepts}

Before discussing further the remaining linguistic forms (seasons, years, months) which are nuclear to the expression of time concepts, I should like to digress briefly in order to consider some of the vehicles which bear these concepts. Of particular interest to the Maya epigrapher are such concept-carriers as action words (chiefly verbs), relators (chiefly locating time in space) and mechanisms for ordering words in pairs, thus creating an imagery which serves as a unique conveyance of concepts (Neuenswander, 1965; Townsend, n. d.).

Even though it has now become known, largely through the scholarly efforts of Proskouriakoff (1960), that the purpose of most inscriptions was to record historical events in the lives of rulers, rather than, as was previously thought, to record time data for the sheer enjoyment of observing "the never-ending flow of days from the eternity of the future into the eternity of the past... to bring into harmonious patterns the circling planets, the changing seasons, the shifting sun, and the errant moon" (Thompson, 1950: 1), this historical data does happen to be embedded in what seems a superfluity of information about time. For this very reason, the recognition of event glyphs was so long in coming, and for this same reason it is worthwhile to examine contemporary time structures in hopes that they might provide fresh insights into the decipherment of enigmatic glyphs.

\section{Action Words}

In reporting ages of individuals, the four verbs which are most commonly used are: 1) $k$ 'is "to finish" (see also previous sections for examples) ; 2) $u k$ 'ah "to bear, as a burden"; 3) ch'ap "to grasp, catch"; 4) mah "to take on": ya xk'is $i$ kahib, ruk'am $i$ ho'ob "he has finshed four years and has taken up five" ("already he-finished the four, its-carrying the five"). The noun cognate form $k^{\prime} a m$ means "carrying net" or "cord" (for measuring land, a day's work, quantity of corn harvested, etc.). Two glyphs, referred to as T90 and T92 (because of their numeration in Thompson's catalog of glyphs, 1962) are phoneticized by Thompson as $t u$ and defined as an affix or particle which is used with periods of time, immediately followed by a number and then by a month name (Thompson, 1950: 196-7). The net trap representation (see Fig. 1) lends itself well to either the verb $c h^{\prime} a p$ "to catch" or the verb $u k^{\prime} a h$ "to carry as a load". Best known to 
scholars of the Maya Script (and especially dear to Thompson's heart) are the full-figure glyphs of men, representing numbers, carrying their burdens of time with tumplines across the centuries. Ch'ap appears in the context of grabbing an object or a unit of time, catching a person (to take prisoner) or an animal (in a trap) or even of being caught by a disease (instead of catching cold, the cold catches you): lahuh 'ih u ch'apik $i$ beleheb ik' chweq "She will be ten days into her ninth month tomorrow" (lit., "ten days her grabbing the nine months tomorrow"). The verb mah is used most commonly to "take a road, begin a trip":

Ya mahom $i$ kahib; pa nima'ih San Pablo $x k^{\prime}$ is $i$ oxib, xu ch'ap $i$ kahib "He was three years old on St. Paul's Day and is now going on four" (lit., "already has-taken-on the four; on big-day St. Paul he-finished the three, he began/grabbed-onto the four").

The verbs "to pass' (ik'aw) and "to arrive" (pet) are used especially in reference to temporary periods such as the observation of a "big day":

Ya xpetik, ya xe ik'awik $i$ ki 'ih i qatit qamam "All Saints' Day has come and gone" ("already they-arrived, already they-passed, the their days the our-grandmothers our-grandfathers").

The verb $t z^{\prime}$ akat "to be complete, full term" is used in many contexts but one example will suffice:

Beleheb ik' 'o che, ya tz'akat i rik'il "She is nine months pregnant, her months are complete" ("nine months she-has to-her, already complete the her-moons").

While many actions are performed on or for other units of time, it is the moon, more than any other time entity, who initiates activities on her own. Her ubiquitous appearance in the inscriptions and codices is multiplied by taking into account that many hand glyphs (not to mention head variants) are doubtless representations of lunar activity. The Achi conceptualize the moon as "walking" (binik) before us, "providing light" (tzunik "shining, looking"), coming this direction ('el-loq), going that direction ('el-bik), getting old (ko'on rih), changing her course (halo, piskilih), returning (tzalihik), and performing many other activities to be detailed in a later section. It is conceivable that some of the above forms will be encountered in the profusion of glyph affixes and main signs which are suggestive of lunar activity.

In view of the frequent use of linguistic devices which are used to 
simplify a count by means of subtracting a number from the next unit to come instead of continuing to count in increasingly large numbers from the last unit initiated, I would expect something more definite in the area of subtraction devices in hieroglyphic calculations than what has been proposed. Although I am aware of Thompson's "count ahead to..." device, it seems more structured to fit English usage than Maya. Some Achi examples are:

Oxib ik' maha' ka k'is hun hunab "He lacks three months for being one year old" ("three months not-yet he finishes one year").

Oxib ik' krah che i keb hunab "He lacks three months for two years of age" ("three months he-wants for the two years").

(Compare counting money: hun centavo krah che $i$ cincuenta "It lacks one penny for fifty cents"; or worms: $x a$ hun, $x a$ keb chik, xel $i$ cien. "It just lacked one or two to have come out a hundred". ["Only one, only two more, came-out the hundred"].)

\section{Relators and Vertical Ordering of Elements}

Phrases which locate events in time are ordered conceptually in a vertical fashion with prior happenings placed below (chuxe" "at its root") an event and subsequent happenings placed above it (puwi/ puha' "on its head"). When an event takes place within or during a given time, it is described as happening chupam "in its stomach/ insides."

Ku riq u 'ih chuxe' $i$ nima' ih "She will be due to deliver before the fiesta" ("She encounters her day at-its-root the big-day").

Xril $i$ rik'il puwi rik'lal hach' chuhyub "She last menstruated after the mountain harvest" ("She-saw the her-moon on-top-of itsmonth-sacred harvest in-mountains").

Chupam $i$ halbal xo'ono ("During (inside-of) the New Year's ceremonies (change-time) it happened.")

Similar to the vertical ordering of Maya mathematical calculations in which smaller units (e. g., days) appear below larger ones (e.g., months, years, 20-year periods, in an ascending order), so an event which occurs "underneath" a time element is known to have preceded it, while an event which occurs "on top of" that element is known to have followed it. An event which occurs "inside of" it, occurs curing or at the same time as that time element is in progress. 
The implications of this information for glyph analysis could be crucial. If we were to posit, as one possible interpretation, that giyphs could be related to one another timewise by positioning a prefix glyph on top of the main element to indicate that an event happened after the time or action indicated by the main glyph, or by positioning a suffix glyph underneath the main element to indicate that an event happened beforehand, or again, by infixing the time relator to indicate a simultaneous occurrence, then the only remaining affix positions are those which occur to the right and left of the main element. What about these?

Thompson's rule of affixation (1950: 37) states that "in the vast majority of cases an affix can be moved from the left to above the main element or vice versa without altering the meaning of the whole one iota... Correspondingly, the affixes to the right and below are generally interchangeable without effect on the meaning of the symbol". Since most glyphs face to the left, then the few time relators which I have recorded in Achi as happening chuwach "at-its-face/ in front of it" should have the same meaning as those relators which happen puwi or puha' "on top of", that is, "after" or "looking to the future". Similarly, those few relators which I have recorded in Achi as happening chirih "at-its-back/behind it" should have the same meaning as those relators which happen cliuxe" "at-its-root/underneath it", that is, "before" or "leaving it behind". Fortunately, in Achi, the "above" and "in front of" relators both mean "after" and could both be regarded as "prefix relators". The "below" and "in back of" relators both mean "before" and may be referred to as the "suffix relators".

Interestingly, this type of positional value system of time relators is not unique to the Cubulco Achi. Apparently in Zinacantan (southern Mexico, Vogt, 1969) as well as among the Kekchi (eastern Guatemala, personal communication with Francis Eachus and Ruth Carlson), time is more often expressed as being "behind" (before) or "in front of" (after) an event than it is as being "underneath" or "on top of" it. The Jacaltec of northwestern Guatemala (personal communication with Jean Stratmeyer) apparently mix metaphors, referring to prior happenings as being "underneath" (as do the Achi) and future happenings as being "in front of" (as do the Kekchi and the Zinacantec). In view of the wide geographical distribution of these phenomena of time rclators being spatially oriented around a central element, it would appear logical to apply this same information to the spatial orientation of affixes around a main glyphic element. The epigrapher should keep in mind that the same forms which relate events in tim r 
to the main element, also are used to locate them in space: above, below, in front of, and behind. This appreciably increases the semantic options available to the epigrapher, providing license to move from the static field of applying a single phonetic reading to a given affix, into the more dynamic field of relating events in either time or space through assigning positional values to affixes.

At the beginning of the section on Vehicles, I said that I would discuss "mechanisms for ordering words in pairs, thus creating an imagery which serves as a unique conveyance of concepts". This mechanism of employing poetic word-pairs and parallelistic speech patterns I explored somewhat in 1965, and hopefully Townsend will go into the subject in greater depth in 1979, so that I will only briefly mention here that this is another area in which the Achi use the assignment of positional value to persons, places or things. Consider the following word pairs, used in religious ritualistic speech:

pawaqan, pa'ab "at-your-feet, at-your-hands" (We are in your service-generally said of being in the service of a particular saint).

chuch ulew, chuch ikah "Mother of Earth, Mother of Heaven" (title for the Virgin Mary).

in chuch, in kahaw "my mother, my father" (my parents, native priest).

qa t't, qa mam "our grandmothers, our grandfathers" (also departed ancestors).

walk'wal, wixoqil "my children, my wife" (my family).

The above examples provide evidence of vertically ordering elements from the bottom to the top according to the order of physical presentation (e.g., feet, then hands; earth, then heaven) and the order of social position (e. g., mother, then father; grandmother, then grandfather; children, then wife). These expressions-common throughout the Maya area-are reflected in the glyphs and ordering should be kept in mind when attempting a reading. Though ordering may differ from place to place (e.g., McArthur, 1977 refers to the ancestors as "our fathers, our mothers" rather than the reverse), certain word pairs are heard all over the Maya area in the same order. Probably the full figure kin (day) glyph of Yaxchilan, which Thompson (1950: 61) refers to as holding the head for six in his outstretched hand and supporting the head for ten on his feet, would be read poetically as bearing an offering in "his feet, his hands" for the god in whose service they were. 


\section{Counting Time by Moons}

The Achi count time by moons on several levels: 1) according to "our grandmother's journey accross the sky", which occupies one complete lunation; 2) according to the "moons"/anniversary celebrations of certain saints and of events in the agricultural cycle, for which the twelve lunations in the year are named; 3 ) according to the moon's control of its water content which determines the beginnings and ends of the rainy season and the dry season-those half-year categories which, when joined, form the year. The year is the highest unit of time represented by a single morpheme which is in use today by the Achi.

\section{Our Grandmother's Journey \\ ( $u$ be i qa tit)}

A determination that is essential to Achi time calculations, and of special interest to parturients is: "In which moon will it come to pass?" Initially, my western frame of reference automatically triggered a transliteration of "moon" to "month" each time I heard the phrase, but when women told me repeatedly that their daughters would deliver in this very "moon", it became increasingly clear that this had no connection with the Gregorian month. The implication was that sometime between the rising of the new moon and the burial of the same moon would come this event. This was referred to as her very own $i k$ ' "moon" by simultaneously prefixing the person indicator (in most cases $r$-, 3rd person sg.) and suffixing the $-i l$ suffix, which is mutually obligatory with the prefix on certain noun roots not usually capable of possession: hence, rikil. When designating a particular "moon" as a time span, however, the form is unpossessed as follows:

Are ik' iri' kin wahik "It is in this moon that I will deliver" ("It-is moon this I-will get-sick").

Ya mero ka petik; we $x k^{\prime}$ is $i$ ik-i' entonces $k a$ petik "It is just about to come; when this moon finishes, then it will come" ("Just about it comes; if completed the month-this, then it comes").

Are $x u$ heq $i$ i $k^{\prime}$, xin heq $i$ wuqub ik'; are $x e^{\prime} e i i k^{\prime}$, xin $k^{\prime}$ 'is wuqub $i k$ " "When began the moon, I began seven moons; when went the moon, I finished seven moons".

To the Achi mind, the moon (qa tit "our grandmother") does not begin a new journey each night, coming out of the east and disappear- 
ing into the west in imitation of the sun's journey. Quite to the contrary, beginning at the time when she may first be distinguished in the western sky before sunset as a very new moon, she is conceptualized as starting on a month-long journey. Beginning this journey $(u b e$ "her road") in the west, her progress is observed nightly at dark as she is seen to have edged her way a little farther eastward from her position at dark the previous night until she finally drops out of sight behind the eastern horizon.

Most adult Achi can quickly inform one of the moon's position in the sky, her size and maturity and her approximate time of rising, if not visible in the night sky before bedtime, and the length of time she will spend in the sky during a given night. Husbands make themselves responsible to keep track of the important events of the yearly religious and agricultural cycles, as well as such mundane affairs as the times of their wives' and daughters' menstrual cycles.

In the following table, I have attempted to coordinate cognitively valid information concerning an Achi lunation, organizing it into four major phases. Phase I covers the period from the new moon to the "half" (first quarter); Phase II, from the "half-grown" to the "mature" moon (full moon); Phase III from the full moon to the waning quarter; and Phase IV from this last quarter to death. The terminology surrounding death of the moon is included as an End Phase. Each phase is considered to last for wukubix "a seven-day period."

There are some concepts implied in Table I which should be made explicit. One concept is that of halo/piskilih "to change, reverse" which in this case applies to the "road of our grandmother." Most Achi consider the halo/piskilih concept somewhat of a mystery. There is no mystery surrounding the first two phases because their grandmother is visible at dark each night from the time she is a child until she is mature. The first seven-day period, she spends climbing higher in the heavens each night until she reaches the tikilik "straight overhead position" at dark-the halfway mark in the visible part of her journey. The next seven days is one of continued growth toward the full-moon size, and is measured by the Achi by how much time she spends in the sky (providing light for night travel and fiestas). At the end of this second phase, she earns imposing title for her accomplishments, hun a'ab u be "one night her road" (full moon). It is at this midway point in the month that the Achi say that she changes her course, hal a'ab "the night changes." She spends less and less time in the night sky, and the light she produces diminishes with her reduction in size. The mystery is concerned with how she got from the eastern sky - after working two weeks to get there from where she 


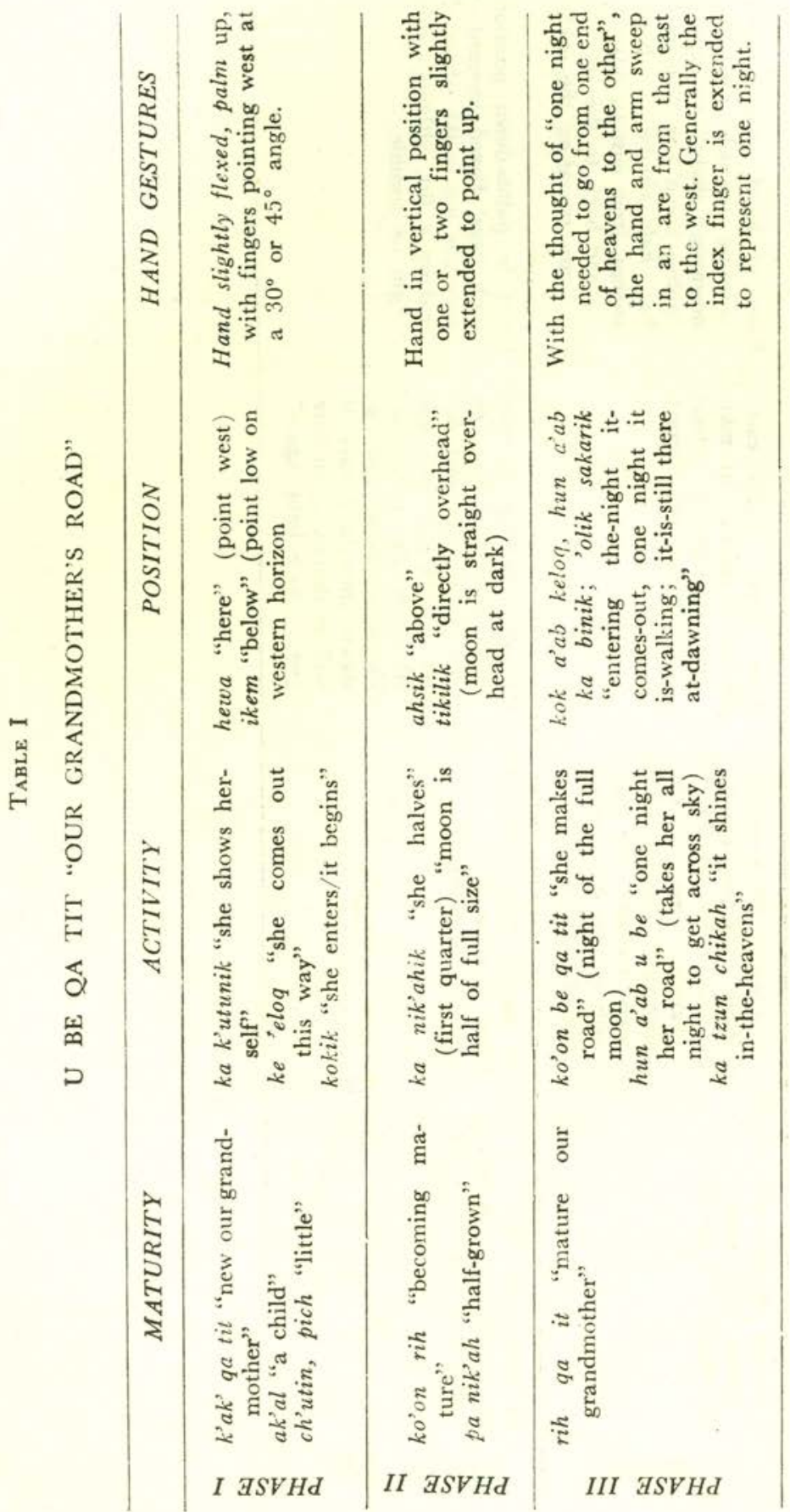

Estudios de Cultura Maya. Vol. XIII, 1981 Instituto de Investigaciones Filológicas/ Centro de Estudios Mayas, UNAM 


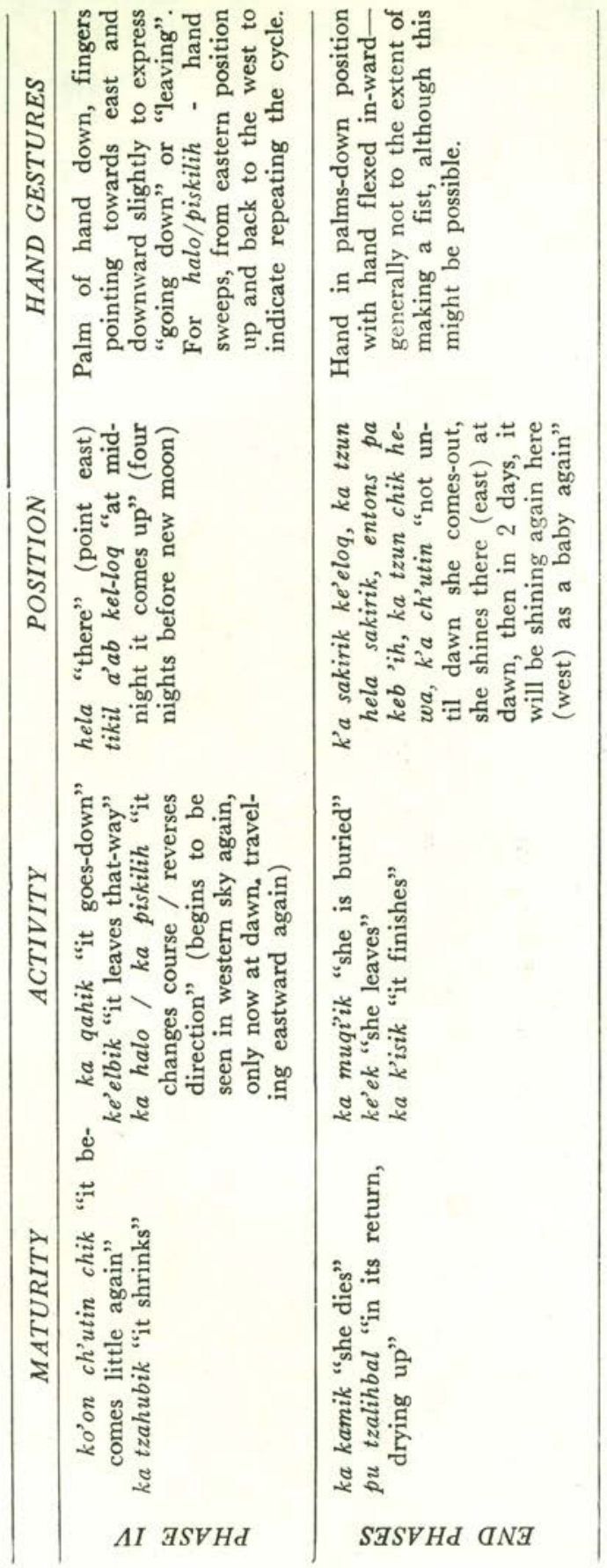


began her journey in the west-suddenly back to the western sky, where she is now observed just as low on the western horizon in early dawn hours as she was formerly observed there in the evening hours. Only now, each morning before dawn, she appears to be pushing her way back to the east again. At the end of her journey, she appears just rising on the eastern horizon at $5 \mathrm{a}$. m., and on this day some might be able to see her again in the evening as a new moon, but most claim that she is buried for one to three days before her reappearance in the west.

Since the $\operatorname{hal}(o)$ "changeover" concept is used also in speaking of changing years (see under January in Table II), of changing seasons, and of changing lengths of days and nights at solstices, we shall discuss it later in relation to Thompson's hel "change" glyph.

Another concept needing clarification concerns the moon's position being described by the words hewa "here", meaning "west" and hela "there", meaning east. My first response to this information was to pair it with information concerning directions, in which north is referred to as being on "my right" (weqabim) and south as being on "my left" (in moxim). Realizing that the north is on the right of a person, only if that person is facing west, I concluded that the same westward lunar orientation which caused the Maya to refer to the west as "here" and the east as "there", also caused them to face westward when they assigned the values of left and right. However, I discovered later that the sun, as well as the moon, comes up hewa "here" and goes down hela "there." In this case, then, hewa refers to east and hela to west.

The discussion of moon phases and hand gestures will be reserved for the section on comparison with hieroglyphic information available in the Lunar Series of the Inscriptions.

\section{The Year, the Half-year, the Seasons, and the Months}

The year (hunab) is divided into half-years (nik'ah hunab), which correspond to two seasons, the rainy (alah) and the dry (sa'ih). Each season is composed of six months. Table II summarizes the information regarding the major saints' days and agricultural events which substitute for the Gregorian months during each season.

The Achi conceive of the time between the Day of the Cross (May 3 ) and the Day of the Saints (Nov. 3) as composing a "half-year": $k i$ ' $i h$ ' 'ih $i$ santos, nik'ha hunab re $i$ crus "their day the Saints, one-half year from the cross". However, they also recognize the time betwoen 


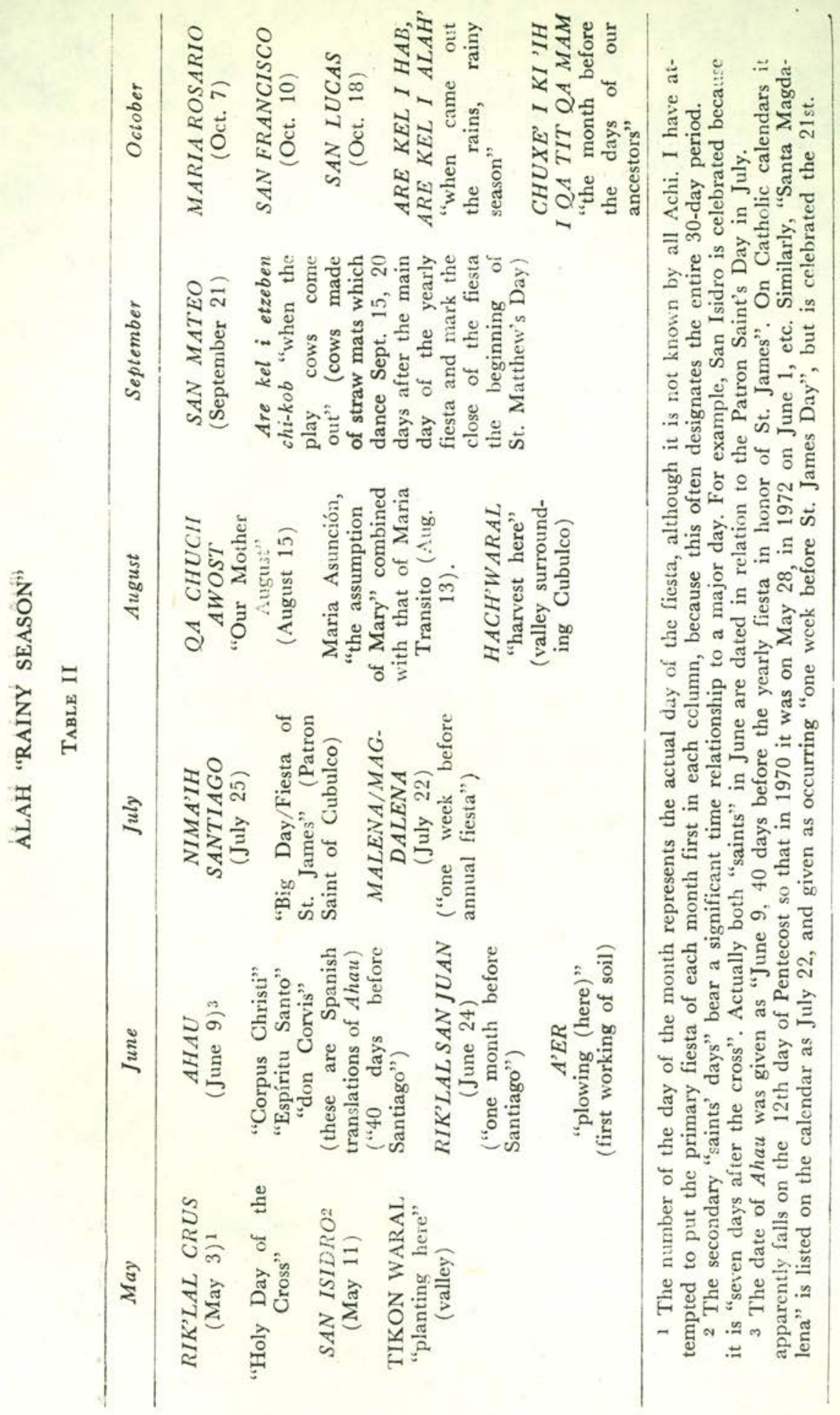

Estudios de Cultura Maya. Vol. XIII, 1981

Instituto de Investigaciones Filológicas/

Centro de Estudios Mayas, UNAM 


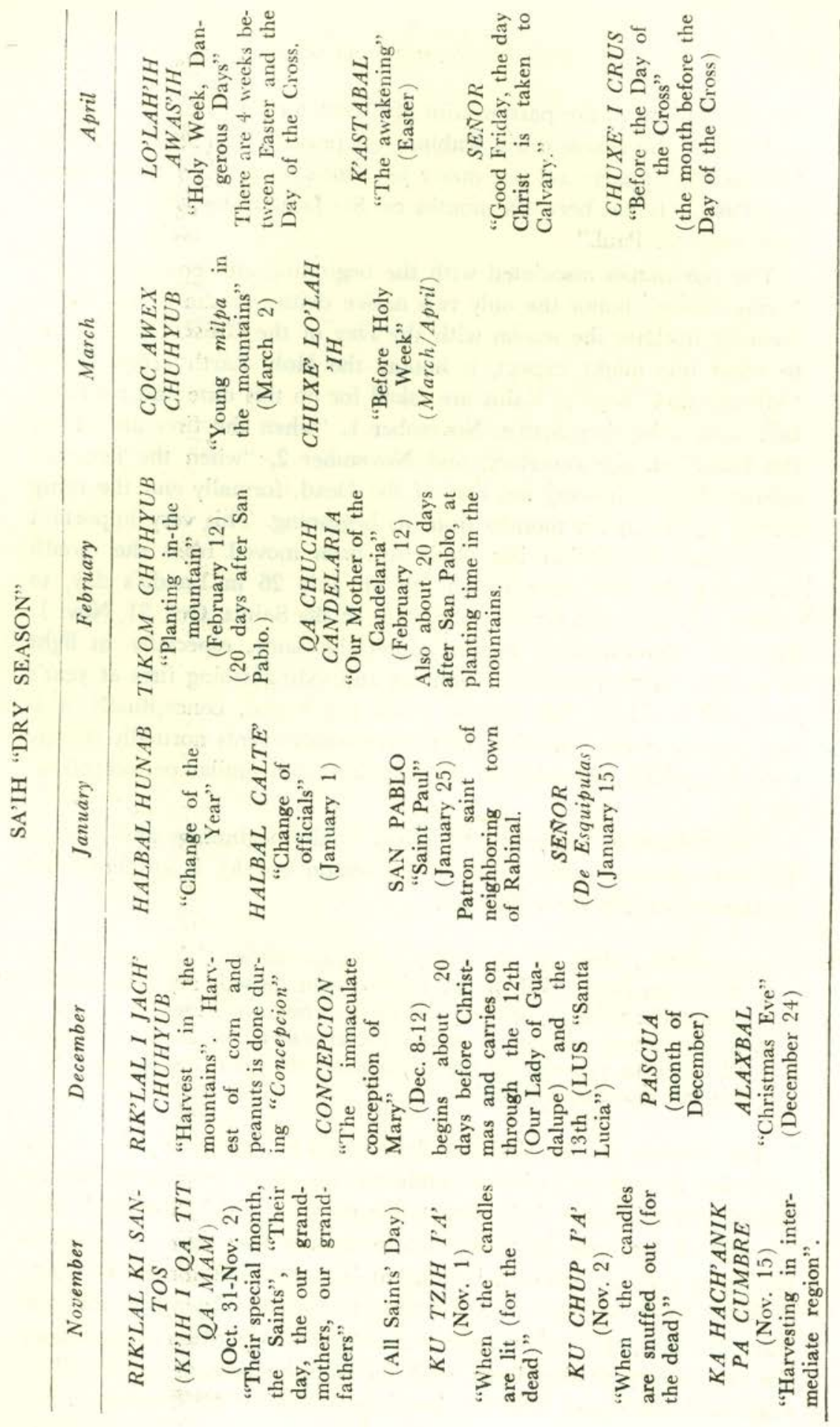

Estudios de Cultura Maya. Vol. XIII, 1981

Instituto de Investigaciones Filológicas/

Centro de Estudios Mayas, UNAM

http://www.iifilologicas.unam.mx/estculmaya/ 
the celebrations of the patron saint of Cubulco on July 25 (St. James) and that of the closest town, Rabinal, on January 25 (St. Paul), to be "six months" apart: xel seis meses pa Santiago, kel hun hunab puwi San Pablo "It has been six months on St. James' Day, it will be one year after St. Paul."

The ceremonies associated with the beginning and end of the alah "rainy season" honor the only two native deities of the Achi. May 3 formally initiates the season with the Day of the Cross, but contrary to what one might expect, it honors the Holy Earth (Hyub-Ta'ah "Mountains-Valleys"). Rains are asked for on this date and routinely thereafter until they arrive. November 1, "when the fires are lit for the Dead" in the cemetery, and November 2, "when the fires are extinguished" following the Day of the Dead, formally end the rainy season at exactly six months from its beginning. This very important ceremonial observation has obviously been moved from the month preceding the new year which fell on July 26 in Landa's day, to conform to the Catholic calendar's Day of the Saints, Oct. 31, Nov. 1. However, the functions remain much the same, especially in light of ancient Maya practice of lighting and extinguishing fires at year's end. While this is two months from year's end, conceptually it is not hard to accept, since important ceremonial events normally occupy a 20-day period preceding an event as well as a similar period follow. ing it.

The division of the year into halves by the beginnings and ends of the rainy season (alah) and the dry season (sa'ih) is authenticated by statements like the following:

Are xik'aw $i$ alah, $x u$ heq $i$ k'ax chwe, are xik'aw $i$ hab pa ki' 'ih qa tit qa mam "When the rainy-season passed, my pain began, when the rains passed, on the days of our ancestors."

$X i n k^{\prime} u n$ awu' chupam $i$ sa'ih; $i$ ' 'ax chwe, ya mero hun sa'ih "I came to you during the dry-season; the pain to-me has lasted almost one dry-season."

The relation of the rainy and dry seasons to the moon came to my attention through use of hand positions, just as had the phases of the moon. When it is dry, it is because the moon is tikilik "upright", with the tips of the crescent turned up in such a way that the water is unable to get out. When it is rainy, it is a sign that the moon is xotolik "lying on its side" with the crescent turned sideways so that the water can get out. To demonstrate the dry season position of the moon, the arm is bent at the elbow, with the forearm vertical and at a $90^{\circ}$ angle with the upper arm; the hand, representing the crescent of the 
moon, is tilted back with the thumb extended so that the concave line thus exposed between the thumb and index finger is capable of retain. ing water. To demonstrate the rainy season, the arm is lowered to a horizontal position so that the water held in the crescent may now run out (see under "Figures"):

I ik' xoto'ik pa 'alah, ka pe i hab; pa sa'ih, tikilik, ka pe ti hab. "The moon is-on-her-side in the-wet-season, it comes the rain; in the-dry-season, it-is-upright, it comes not-the-rain."

The Achi further explain that during the dry season, the "stomach" of the moon steadily increases because of the rain content and it is surrounded by clouds, while in the rainy season it becomes small:

Sa'ih, nim chik u pam i ik', maha' ka pe i hab, 'o sutz ru', kawil yet, 'o hab chupam. Alah, ch'utin u pam, xotol i nan. "Dry-season, big already her stomach the moon, not-yet it comes the rain, there-exist clouds with-it you-see you (it looks like to you), thereexists rain in-her-insides. In-the-rainy-season, little her stomach, lying down the mother."

\section{Solstices}

Surprisingly, still another astronomical cycle is indirectly related to lunar activity through its convergence with the rainy and dry seasons. Running in an almost identical cycle with the seasons are the solstices. From our etic view, the rainy season begins in May and the longest day and shortest night of the year-the summer solstice-occur about June 22; the dry season begins, theoretically, in November and December 22 marks the shortest day and longest night of the year - the winter solstice. The Achi are aware that the sun is in the south in the beginning months of the dry season and in the north in the beginning months of the rainy season. The concepts which find fullest linguistic expression are concerned with the size of "our father", the sun, his position (he, too, lies on his side), his sudden conversion from one length of day to another, and his relationship to the seasons:

$P a$ alah, ch'utin u pam $i$ 'ih; xotolik $i$ 'ih pa 'alah "In the rainy season, the days are short; the sun rests on his side" ("In rainyseason, small his insides the sun; lying-on-his-side the sun in rainy season.")

$P a$ sa'ih, nim chik $u$ pam $i$ 'ih "In the dry season, big again his stomach the sun/day". 


\section{May-June}

Nimaq u'ih, ronhel $i$ ik', Mayo "Big its days, all the month of May." Are ka piskilih i fecha $i$ Junio, ko'on chik ch'utin $i$ ' ih "When the date changes to June, become small again the days."

\section{December-January}

Pa alaxbal, ch'utin upam qu kahaw "At Christmas, small its stomach our father".

Pa San Pablo, ka piskilih, kel'ih hewa, ha qahik hela "On St. Paul's it turns around, comes out the sun here, it goes down there."

Pa alaxbal, ch'utin u pam qa kahaw "At Christmas/birth-time, little his stomach our father" (short days).

Are a'ab nah u pam, are pa 'ih ch'uinin $u$ pam. "Then the nights are long and the days short" (Then the night long its stomach, then at day, small its stomach").

Pich u pam a'ab pa san Pablo, nah u pam qakahaw "But in January, the nights are short and the days long" " "Small its stomach the night at St. Paul's, long his stomach, our father").

From the above examples, it becomes plain that the solstitial concept of the Achi is not one of a gradual lengthening of days up to the summer solstice, at which time they gradually lessen in length. Rather, we are back to the piskilih/hal concept of sudden conversion: days are short and nights are long at Christmas. One month later (San Pablo-Jan. 25) they suddenly "change" and days become long and nights short. In June, the process reverses and the days become "short" (on what is, to the Westerner, the longest day of the year). Another application of the concept of "grabbing onto the pattern-to-come" seems to be working here.

\section{Saints' Days and Agricultural Activities}

Having lost their calendar specialists, the Achi were able to replace the twenty day names of the 260-day divinatory calendar and the eighteen month names of the 365-day solar calendar with the names of the saints used by the new calendar specialists, the Catholic priests. One need read only a few lines from the writings of such priest-ethnologists as Bishop Diego de Landa to discover that the priests themselves used the names of saints in preference to month names of the Julian calendar-the calendar in use at that time: 
The sun never hides itself nor goes far enough away from this land of Yucatan so that the nights ever get to be longer than the days; and when they are longest, they are wont to be of equal length from Saint Andrew to Saint Lucia, when the days begin to grow longer (Tozzer, 1941: 132).

Tozzer's research turned up December 10 to December 23 as being the corresponding Gregorian dates. While the idea seems to have resulted from a poor translation of Maya cognition surrounding the winter solstice, it helps clarify the origin of such obscure saints' names as St. Lucia, which still marks Dec. 23, the date of the winter solstice in Cubulco.

The functions of the day and month deities and the ritualistic ceremonies performed in their honor also remain much the same. Saints are conceived of as watching over the group for certain time periods and are referred to as "the owners" of these periods. Whenever it rains on a saint's day, the immediate response is that it came from the saint in charge. Ceremonies in the honor of saints still are for the purpose of "elevating their day/their birth" in the poetic language still implied in the inscriptions: qa yak'bal $u$ 'ih, yak'bal ralaxik "our raising-means his day, raising-means his birth."

Dates of astronomical significance seem to be represented quite consistently by certain saints' names all over Mesoamerica:

August 12-13, zenithal sun position, zero point of longcount calendar, new-year's date originally, still called halbal in Cubulco (word for new year in January now), but people connect the phrase to its homophonous form, "time of young corn" in Cubulco at this time of year (hal "change, young corn"). The date honors "our mother August", though actually two saints represent her: María del Tránsito on August 13, and María Asunción on August 15. This would have facilitated a change-time where one deity gave over the charge to the other.

September 21 ostensibly honors St. Matthew, but the autonal equinox was probably the covert reason for the choice of saint.

October-November-All Saints' Days, is an important time for honoring the ancestors all over the Maya area.

In December, the Virgin of the Immaculate Conception, Concepción, is honored in a varying date between the eighth and the twelfth. Her celebration marks the end of the harvest of mountain corn, "which takes nine months to bear, even as our grandmother, the moon, takes nine months to bear." One is left with the distinct impression that the saint called Concepción is very closely related, in the minds of the Achi, with our grandmother, the moon, and with the 
mountain corn. She is often shown emerging from a snail's shell in the large processions which precede Christmas. Strangely, there is a huge exodus of Cubuleros to work on the coastal plantations on the day after Concepción, hence largely ignoring the Christian holiday of Christmas. The main concern is that they should return in time for the celebration of St. Paul's Day, Patron Saint of the neighboring town of Rabinal, which barely allows them time to prepare the fields for planting the next crop in February. The planting is overseen by the Virgin, Maria Candelaria, who is also celebrated about the twelfth of the month (as was Concepción two months earlier).

In March, the sprouting of the young cornfield in the mountain precedes the vernal equinox and Holy Week activities, which generally extend into April. Easter time marks "four weeks before the Day of the Cross" (May 3) and the beginning of the rainy season. As mentioned previously, it is the carth god who is given major tribute in May, as the prayers entoned to him so eloquently express:

Only because of the earth exists our tortilla, exists our drink;

Because the earth maintains us, it nourishes us,

It nourishes our cows, it nourishes our horses;

It nourishes our chickens, it nourishes our pigs.

Because the earth nourishes and feeds us,

We are here; here it is we were born, here it is we blossomed

Here it is we will die, here it is we will perish. $[($ poik);

June has the distinction of being the only month which bears the name of a Maya Day Name (Ahau). Ahau means ruler in Achi and its derived forms, r-ahau, kahau, and q-ahw-al signify "owner, father, and our-lord", respectively. Its connection with the sun in the inscriptions, and the fact that June 22 marks the summer solstice may be related. Also the fact that, in Landa's day, the new year fell in July and the ahau day name- a favored one on which to end a cyclemay have been a suitable one for year's-end ceremonies. It is equated in Spanish with the Corpus Christi/Holy Spirit/Pentecost observations which one Achi said were called "don Corvis", but hastened to assure me that the real name for the observations was "Ahau."

July, then, brings us around one complete cycle. The fact that

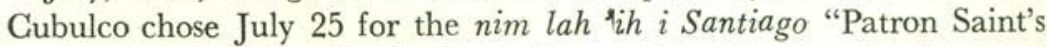
Day" ("big very day the St. James") may be related to the fact that July 26 was the day to which the Maya New Year (0 Pop) had rotated by Landa's time in the 1500's (Tozzer, 1941). The July 26 date is the focal point of the year, so that by merely saying chuxe' $i$ nim $i$ 
'ih, or puwi i nim $i$ 'ih "before/after the big day", all are advised of the exact location in time within the year.

\section{Hieroglyphic Structures}

In the beginning, I proposed the hypothesis that the Maya layman has retained, from earliest times, a high level of proficiency in the art of telling time and that the unit upon which his most exacting calculations are based is now, as then, the lunar cycle. In order to test this hypothesis, we have, up to this point, concerned ourselves almost exclusively with exploring the cognitive structure of time held by the Achi of Cubulco. We are now ready to consider the hieroglyphic structures known as the lunar series, after which we will be in a better position to consider any possible similarities between the current and ancient structures which might imply survivals.

Inscribed on the monuments of the Initial Series Period are a group of glyphs known as the lunar series, which either come between the day and month glyphs or follow them. They have been assigned letters of the alphabet A through $\mathrm{G}$, plus $\mathrm{X}, \mathrm{Y}$, and $\mathrm{Z}$, though $\mathrm{F}$ and $\mathrm{G}$ are not an integral part of the system. They occur in the following order (in the exceptional cases where all are present): day sign, Glyphs G and $\mathrm{F}$, month sign, E, D, C, X, B, and A, with glyphs $\mathrm{Y}$ and $\mathrm{Z}$ inserted between $\mathrm{F}$ and $\mathrm{E}$ when they occur. Glyphs $\mathrm{A}, \mathrm{B}$, and $\mathrm{X}$ were later additions to the series. Teeple deciphered glyphs C, D, and E, which are nuclear to the group (1925, 1925a, 1930), drawing heavily from the amassed information of Morley $(1915,1916)$, who had provided an excellent background for these discoveries. Thompson (1929) concentrated first on glyphs F and G, and has since been largely responsible for adding new information.

Very briefly, research to the present fairly well establishes that:

Glyph A indicates the actual or expected age of the moon-whether 29 or 30 days - during the month referred to on the inscription.

Glyph $\mathrm{C}$ indicates the number of moons that have elapsed in a given half-year of six moons (numbers the moons, 1, 2, 3, 4, 5, 6, 1, 2, 3, etc., continuously).

Glyphs D and E together indicate the number of days that have elapsed since the last new moon.

Glyphs $\mathrm{Y}$ and $\mathrm{Z}$ are inserted between glyphs D and $\mathrm{E}$ and their coefficients; glyph $\mathrm{Z}$ is what has been referred to as the "bix" (5-to 7-day cycle) glyph.

Glyphs F and G together indicate, supposedly, which of the nine 
"Lords of the Night" were ruling on a given night (composed of a continuously revolving cycle of nine glyphs).

Glyphs B and X are still highly speculative. B is referred to as the "elbow glyph" and is generally considered to indicate some astronomical phenomenon as "eclipse" or "Venus cycle". Glyph X should probably be read together with Glyph C or B (appearing between the two).

\section{General Insights Provided by Comparing Current and Early Structures}

In the section on Relators and Vertical Ordering of Elements, I noted the Achi system of assigning a place/positional value to time relators so that actions placed "underneath" or "behind" an event impiied prior action while actions placed "on top of" or "in front of" an event implied subsequent action. I suggested that the implications of this information for glyph analysis could be crucial, in that glyphs could be related to one another timewise by positioning a prefix glyph on top or to the left of the main element to indicate subsequent action or by positioning a suffix glyph underneath or to the right of the main element to indicate prior action. After making that statement, I discovered a very unexpected application of this rule to the positioning of coefficients within the lunar series phrase.

My analysis is based on Figures 36 and 37 of Thompson (1960), where he thoughtfully provided the lunar series glyphs within the context of the entire phrase, rather than in their usual isolated states. Each phrase begins with Glyph D, which has either over it or to its left the coefficient indicating the age of a particular moon. The coefficent may be either numerical (bars and dots) or it may be the lunar crescent which indicates a coefficeint of twenty days, to which later may still be added a further numerical coefficient. In either case, since it is understood that Glyph E is only a numerical coefficient of Glyph D, the coefficient to the left or above Glyph D implies that other glyphs follow in the same series. Each phrase then ends with Glyph A (with one exception of a misplacement of Glyph B), which always positions its coefficient to the right or below the main sign. The coefficient of Glyph A may be numerical (bars and dots) or it may be the head variant sign for number nine or ten; in either case, it always appears to the right of, or below the final glyph.

Whether the prefixation of the first glyph and the suffixation of the last glyph in a series indicates subsequent and prior time or 
whether it is simply a mechanical device for indicating to the reader the beginning and end of the phrase is not central to this particular discussion. Rather, I would like to point out that this method of positioning coefficients within a phrase to indicate its beginning and end points, illustrates clearly one way in which an understanding of the cognitive structuring of elements may influence their analysis.

\section{Lunar Series from Piedras Negras}

(Thompson, 1960, Fig. 36, 44-48)

I believe that, if there were sufficient time and space to do so, it could be proved that all of the glyphs within the lunar series are inter. dependent - not only $\mathrm{C}$ and $\mathrm{X}$, or $\mathrm{C}$ and $\mathrm{B}$, but the beginning glyph $\mathrm{D}$, and the ending glyph $\mathrm{A}$, and all glyphs in between. Often, when a wavy sky line occurs in one, it recurs in each, or when a youthful head or a skeleton head occurs in one, it tends to be reduplicated in each. I feel that this is probably due to the fact that they are bound together linguistically by a discontinuous morpheme as indicated by the positioning of prefix and postfix coefficients. For example: A common linguistic form is:

"This is what we have done-this",

in which the beginning and end "this" bind the phrase together.

Glyph C, which indicates the number of months advanced into the lunar half year is one of the most consistent glyph forms. It includes a numeral coefficient of up to six months. An extended hand points always to the right, as if to suggest incorporation of information on following glyphs. It touches what is generally referred to as a lunar postfix on the right and generally has the head of either a skeleton or a young man above the outstretched hand to which one is tempted to assign the title for "rainy season" (alah) ("young boy"-ala) or "dry season" (sa'ih) ("comes the sun"), so that it could read:

ohob ik' chu'ab/pu'ab i alah/sa'sh "five months in the hand of the rainy/dry-season ( $p u^{\prime} a b$ and $c h u^{\prime}$ $a b$ show authority as in pu'ab $t$ Dios "in the hand, under the authority of God"). 
Somethimes there is a "Venus sign" or a "fish" or rain sign attached as a prefix-one which normally accompanies Glyph B. I would read the Venus sign as 'sa'ih and the fish or rain signs as alah, dry and rainy seasons, respectively, though it is probable that both could be present simultaneously, in case of a drought.

Glyph C-3

T. Fig. 36,40

\section{GLYPH D.E: A Report of}

"Our Grandmother's Road"?

Teeple's decipherment of Glyph D (1930: 46) as showing the age of the moon, i. e., the number of days that have elapsed since the last new moon, has been generally accepted. The mystery consists in the assignment of meanings by Thompson (1950: 239) to the variants of Glyph D, one of which was "uncertain" and the other six which meant "completion" or "death of the mocn", especially in view of the fact that he had been one of the major proponents of counting a lunar cycle from the new moon. If we were to examine Glyph D with its coefficient, showing the number of days since the last new moon in the light of how present-day Maya would speak about "our grandmother's road", we find the following general patterns emerging:

Glyph C-5

T. Fig. 37,24
Glyph D-4

T. Fig. 36,57

1. Glyph D with a coefficient of 1-8 (ak'al "child" stage covering from birth to "half") taken from Thompson (1950: 237) has the following distinctive features:

"The forefinger usually points diagonally to the right; the other 
fingers are usually bent. On the right there is half of the normal moon sign but with three dots, arranged diagonally, replacing the circle generally found in the in. terior of the moon sign. A postfix, the attributive il sign is beneath the hand or underlies both hand and half-moon sign."

The Achi expression for this hand sign is: kel ikem, ke'e ahsik "It leaves from below and goes toward and goes toward above."

We should take note, before proceeding, that erroneous labeling of glyphs often confuses the analysis. One aid to analysis which is helpful to me, but I have not read of it being used by others, is counting the dots in any of the lunar representations and assigning a value of five to each dot.

At the five-day stage of growth, when the moon is nearing mid-sky (tikilik) or the halfway position ( $p a$ nik'ah), one glyph appears which Thompson labels "2-D?" which is probably a bar representing "five" broken in half and a vertical hand touching it. This glyph closely resembles the Achi hand position for the second phase of lunar activity - when the moon is directly overhead.

2. In the grouping of glyphs which one would expect to reflect the growth from half to full moon, there is no Glyph D-9 available to me (that marked by Thompson as such is really 29 , I believe). Glyph D-10, as one could expect from a multiple of the basic 5-day period, is an unusual form -apparently the birth date in.
Achi

Rising young moon

T. Fig. 36, 6

Reads D-9;

(I read D-29)

Glyph D-5, T. Fig. 37, 41

Estudios de Cultura Maya. Vol. XIII, 1981

Instituto de Investigaciones Filológicas/

Centro de Estudios Mayas, UNAM 
dicator suggested by Proskouriakoff (1960), which I would read: lahuh 'ih chuxe' $i$ po'bal $i$... "ten days before the birth of...", or if the suffix is actually an -il suffix, as Thompson suggested, it may be read: lahuj 'ih po'naq chik $i$ rik'il i... "ten days borm already the its-month the ... (continue on to next glyph). Other than this "oddity", we may add a new type of glyphic representation for the phase between 8 and 15 days in the current moon to say that our grandmother has passed the halfmoon mark and is walking towards full moon: "one night her road." Looking at this glyph through Achi eyes, the interpretation changes. The lunar disc now has the bottom section partially cross-hatched and the "road" across the sky is symbolized by a continuous circlet over the crescent opening. Two large eyes symbolizing her showing herself at dark on the castern horizon, walking all across the sky, and still being large and bright at dawn in the western horizon. This glyph only appears with glyphs representing days 11 through 15 of the current moon. A variant appears on the 15 th day, the real day of the full moon, which perhaps represents her route across the night sky (see figure).

3. After the fifteenth day of the current moon, the next record which I have in my possession, is D.18,
Achi 7-day old moon, halfway across sky, (pa nik'ah)

Glyph D-11, T. Fig. 37, 23

Glyph D-15, T. Fig. 37, 48

Glyph D-18, T. Fig. 36, 11

Achi

Moon going down 
by which time the back of the hand is exposed as in a going. down position, and the lunar crescent is again waning and crosshatched. The nineteenth day may show the frog glyph again, or a hand with one finger extended as if to say-through its suffixthat it lacks one to complete the 20-day cycle pointed out by the finger.

4. From the twentieth day through the end of the cycle, a numeral coefficient may be added to the 20-day moon sign, with or without an accompanying hand sign

\section{Conclusions}

There are, of course, many concepts apparent in contemporary Achi struc. tures which may be survivals of concepts appearing in hieroglyphic structures, but probably the one which has more profuse hieroglyphic representation than most is the hal/piskilih "change, turnover" concept. Judging from its use by the Achi, it may refer to a night $\left(a^{\prime} a b\right)$ to mean the change from a full to a waning moon; to the seasons (alah, sa'ih) to indicate a change from one to the other; to the year (hunab) to indicate a change in the authority structure and the time counting; and to the solstices, to indicate when the days and nights change length. This is accomplished in the glyphic representations by changing the affixation which normally occurs with the hal (Thompson's hel) glyphs. I be-
Glyph D-19, T, 37, 7

Achi

Moon going down

Glyph (D)-E, T. Fig. 4, 16 Balak hal/piskilih

Summer solstice: days become short and nights long 
lieve that Glyph B of the lunar series also indicates the hal/piskilih concept through the manifestations of the elbow glyph, because the motion that is made by the Achi to explain the concept sweeps across the sky from one extreme to another to indicate the moon "turning over" or to show the change in hand positions for the moon's control of the rainy season and dry season. Understanding Achi cognition makes it perfectly reasonable to expect that, through a single glyph such as the elbow glyph, one could express all moon-controlled activities mentioned above plus the eclipse information, on which the lunar half-year came to be based.

There are a variety of glyphs which, I believe, represent the rainy season -dry season, complex, mainly through the use of hand positions. This is probably due to the fact that "your hand" (a'ab), "night" $\left(a^{\prime} a b\right)$ and year (hunab) are very closely related, if not homophonous, in Maya languages. The hand with a cloud-like cover and water droplets (Kelley, 1976, Fig. 59) eloquently expresses the Achi concept of the dry-season moon:

i ik' 'o sutz' ru' nim u pam sa'ih, kel ti ya che "The moon has clouds on it, it gets big during the dry season because the water can't get out."
Winter solstice: days become long and nights short sa'ih "dry season moon"
Kelley, Fig. 59
Achi hand position for dry season (sa'ih); moon in upright-position to retain water (tikilik)
Achi hand position for rainy season (alah); moon on her side (xotolik) to allow water to escape piskilih $a$ 'ab "turns over the night" (full moon)

Kelley, Fig. 12 
In conclusion, I would like to state that cognitive studies should not only reveal similarities between structures, but should also reveal concepts not found in contemporary Maya structures which are therefore suspect in the glyphs. A few of these are:

1. A multiplicity of gods. The Achi pray mainly to the earth and ancestors. I feel we should talk less of "God K", etc., and more of figurative representations of a concept.

2. The nine Lords of the Night. In light of a complete lack of evidence of such a concept now, I would question the authenticity of this concept. Instead, I would explore very carefully a nine-moon cycle. The Achi say, "The moon conceives every nine months,- -like a woman,-like mountain corn."

Thompson's evidence that these recur in a nightly train is perhaps not completely authenticated, in that he said that knowledge of these lords helped him to fill in missing dates in more cases than not, and that they generally appear only on katun endings, which were supposed to be almost always the same for any cycle divisible by nine.

3. Since time is almost always crunted by the period just begun, rather than the one just completed, it would appear that the array of diverse hand positions proposed by Thompson and others, all meaning "completion", is not realistic in the light of contemporary Achi structures.

Acknowledgments: I wish to express my profound gratitude to Jean Bates for typesetting copy for this paper and to Dorothy Marshal for drawing the illustrations.

\section{REFERENCES CITED}

Dumont, Jean-Paul

1972 Under the Rainbow: Nature and Supernature Among the Panare Indians. Austin: University of Texas Press.

Estrada Monroy, Agustín

1972 "Lenguas de las doce provincias de Guatemala en el Siglo xvir". Diario El Imparcial, 27 de abril de 1972. To form Chapter 1 of Tomo 7 of Enciclopedia Paleográfica Guatemalteca. Gua. temala City.

Kelley, David Humiston

1976 Deciphering the Maya Script. Austin: University of Texas Press. 
KNorozov, YURII V.

1958a "New Data on the Maya Written Language". Proceedings of the Thirty-second International Congress of Americanists (Copenhagen, 1956), pp. 467-75. Manksgaard, Copenhagen.

$1958 \mathrm{~b}$ "The problem of the Study of the Maya Hieroglyphic Writing". American Antiquity, Vol. 23, No. 3, pp. 284-91. Salt Lake City.

Lounsbury, Floyd G.

1973 "On the Derivation and Reading of the 'Ben-ich' Prefix". In Benson, Elizabeth P., Ed., Mesoamerican Writing Systems. Dumbarton Oaks Research Library and Collections. Washington, D. C., pp. 99-143.

McArthur, Hakry

1977 "Releasing the Dead: Ritual and Motivation in Aguacatec Dances". In Neuenswander, Helen L. and Dean E. Arnold (Eds.), Cognitive Studies of Southern Mesoamerica. Dallas, Texas: SII. Museum of Anthropology, Pub. No. 3, pp. 3-33.

Mayers, Marvin K. (Ed.)

1966 Languages of Guatemala. The Hague: Mouton. Also in Lenguas de Guatemala. Guatemala: Seminario de Integración Social Guatemalteca, Publicación No. 20.

Morley, Sylvanus Griswold

1915 An Introduction to the Study of the Maya Hieroglyphs. Bureau of American Ethnology, Smithsonian Institution. Bulletin 57. Washington, D. C. (Reprinted for 1975 edition by J. Eric S. Thompson with a new Introduction and Bibliography. New York: Dover Publications.)

1916 "The Suplementary Series in the Maya Inscriptions". In Holmes Anniversary Volume, pp. 366-96. Washington, D. C.

Nash, Manning

1957 "Cultural Persistences and Social Structure: The Mesoamerican Calendar Survivals". Southwestern Journal of Anthropology, Vol. 13, No. 2, pp. 149-155. Albuquerque: University of New Mexica

Neuenswander, Helen

1965 "Dualism: A Linguistic and Cultural Phenomenon among the Achí". Unpublished Paper presented to the Socio-Linguistics class at the University of Texas at Austin.

Proskouriakoff, Tatiana

1960 "Historical Implications of a Pattern of Dates at Piedras Negras, Guatemala". American Antiquity, Vol. 25, No. 4, pp. $454-475$.

Spinden, Herbert J.

1924 The reduction of Mayan dates. Papers of the Peabody Museum of American Archaeology and Ethnology, Vol. 6, No. 4. Cam-

TEePle, J. E. bridge, Mass.: Harvard University.

1925 "Maya Inscriptions: Glyphs C, D, and E of the Supplementary Series". American Anthropologist, 27: 108-15.

1925a "Maya Inscriptions: Further Notes on the Supplementary Series". American Anthropologist, 27: 544-9.

1930 Maya Astronomy. Carnegie Institute of Washington, Pub. 403, Contribution 2, Washington.

Thompsos, J. ERIC S.

1929 "Maya Chronology: Glyph G of the Lunar Series". American Anthropologist, n. s., 31, pp. 223-231.

1950 Maya Hieroglyphic Writing: Introduction. Carnegie Institution of Washington, Publication 589. Washington. 
1960 Maya Hieroglyphic Writing, reproduced by Norman: The University of Oklahoma Press.

1962 A Catalog of Maya Hieroglyphs, Norman: The University of Oklahoma Press.

Townsend, PAUL

1979 "Couplets and Figures of Speech in Ixil Sacred Oral Literature". Paper presented to the XLIII International Congress of Americanists. Vancouver, Canada.

Tozzer, Alfred M. (Ed.)

1941 Landa's Relación de las Cosas de Yucatán. Papers of the Peabody Museum of American Archaeology and Ethnology, Vol. XVIII. Cambridge, Mass.: Harvard University.

Vogt, Evon Z.

1964 "The Genetic Model and Maya Cultural Development". In Vogt, Evon Z. and Alberto Ruz L., Eds., Desarrollo Cultural de los Mayas. Universidad Nacional Autónoma de México. México, D. F.

1969 Zinacantan: A Maya Community in the Highlands of Chiapas. Cambridge: The Belknap Press of Harvard University Press. 


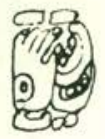

Glyph D.5, T. Fig. 37, 41

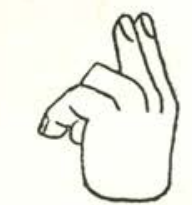

Achi 7-day old moon, halfway across sky, (Ds nik'ah)

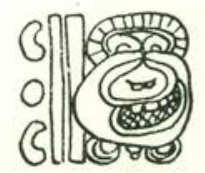

Glyph D.11, T, Fig. 37, 23

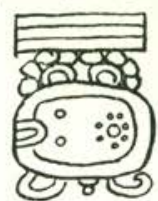

Glyph D-15, T, Fig. 37, 48

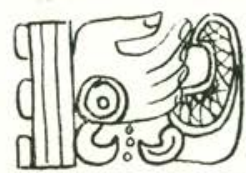

Glyph D-18, T, Fig. 36, 11

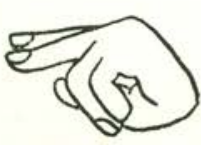

Achi

Moon going down

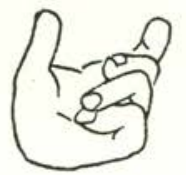

Achi hand position for dry season (sa th) ; moon in upright-position to retain water (tikilik).

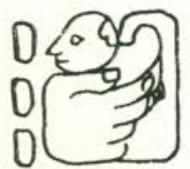

Glyph C. 3 T, Fig. 36,40

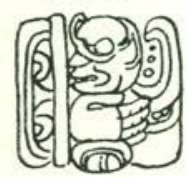

Glyph C.5 T, Fig. 37. 24

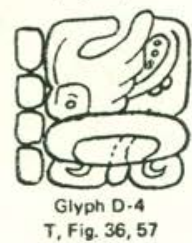

T. Fig. 36, 57

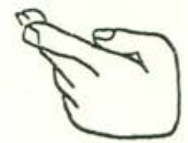

Achi

Rising young moon

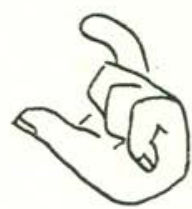

Achi hand position for rainy season (siah); moon on her side (xorolik) to allow water to escape
Achi Time Concepts

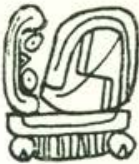

hal/plekillih

Summer solstice: days become short and nights lone

Kelley, Fis. 59

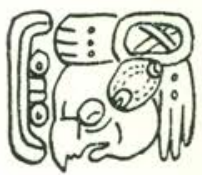

Winter rolstice: days become long and nights short

T, Fig. 36, 9; Glyph B
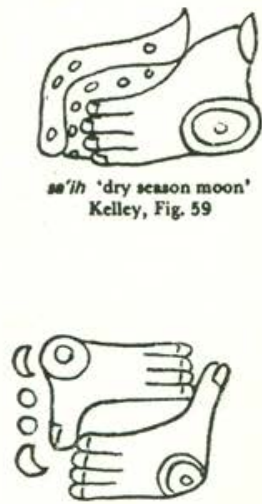

piskilith e'ab 'turns over the night' (full moon) Kelley, Fig. 12 
FIGURE, 1

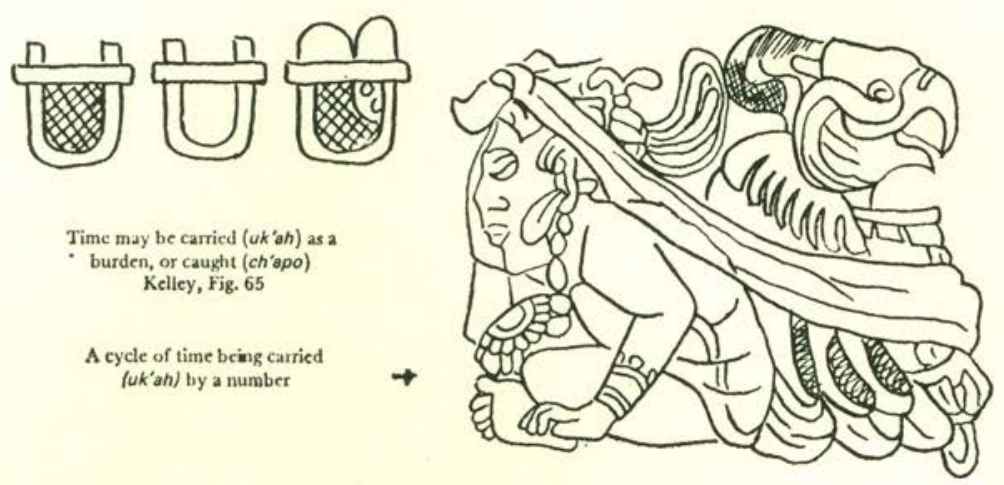

